\title{
Levels of rare earth elements, heavy metals and uranium in a population living in Baiyun Obo, Inner Mongolia, China: A pilot study
}

\author{
Zhe Hao ${ }^{\mathrm{a}, \mathrm{b}, \mathrm{c}}$, Yonghua $\mathrm{Li}^{\mathrm{a}, \mathrm{b}, *}$, Hairong $\mathrm{Li}^{\mathrm{a}}{ }^{\mathrm{b}}$, Binggan Wei ${ }^{\mathrm{a}}$, Xiaoyong Liao ${ }^{\mathrm{a}, \mathrm{b}}$, Tao Liang ${ }^{\mathrm{a}, *}$, Jiangping $\mathrm{Yu}^{\mathrm{a}}$ \\ ${ }^{a}$ Key Laboratory of Land Surface Pattern and Simulation, Institute of Geographical Sciences and Natural Resources Research, Chinese Academy of Sciences, Beijing 100101, China \\ ${ }^{\mathrm{b}}$ Beijing Key Laboratory of Environmental Damage Assessment and Remediation, Beijing 100101, China \\ ' University of Chinese Academy of Sciences, Beijing 100049, China
}

\section{H I G H L I G H T S}

- Representing the first human biomonitoring study carried out in Baiyun Obo deposit.

- Levels of urinary REE, HMs and U were obtained in a population living in Baiyun Obo.

- HMs and $\mathrm{U}$ in the population increased concomitantly with increasing REE levels.

- Individual factors such as gender and age contributing to the inter-individual variation.

- Males and people in the young group were more sensitive to REE, HMs and U exposure.

\section{A R T I C L E I N F O}

\section{Article history:}

Received 16 June 2014

Received in revised form 21 October 2014

Accepted 29 January 2015

Available online 19 February 2015

Handling Editor: A. Gies

\section{Keywords:}

Rare earth elements

Heavy metals

Uranium

Morning urine

Inter-individual variation

\begin{abstract}
A B S T R A C T
The Baiyun Obo deposit is the world's largest rare earth elements (REE) deposit. We aimed to investigate levels of REE, heavy metals (HMs) and uranium (U) based on morning urine samples in a population in Baiyun Obo and to assess the possible influence of rare earth mining processes on human exposure. In the mining area, elevated levels were found for the sum of the concentrations of light REE (LREE) and heavy REE (HREE) with mean values at 3.453 and $1.151 \mu \mathrm{g} \mathrm{g}^{-1}$ creatinine, which were significantly higher than those in the control area. Concentrations of HMs and $U$ in the population increased concomitantly with increasing REE levels. The results revealed that besides REE, HMs and U were produced with REE exploitation. Gender, age, educational level, alcohol and smoking habit were major factors contributing to inter-individual variation. Males were more exposed to these metals than females. Concentrations in people in the senior age group and those with only primary education were low. Drinking and smoking were associated with the levels of LREE, $\mathrm{Cr}, \mathrm{Cu}, \mathrm{Cd}$ and $\mathrm{Pb}$ in morning urine. Hence this study provides basic and useful information when addressing public and environmental health challenges in the areas where REE are mined and processed.
\end{abstract}

(c) 2015 Elsevier Ltd. All rights reserved.

\section{Introduction}

Rare earth elements (REE) refer to the 15 lanthanides including lanthanum (La), cerium (Ce), praseodymium (Pr), neodymium $(\mathrm{Nd})$, promethium $(\mathrm{Pm})$, samarium $(\mathrm{Sm})$, europium $(\mathrm{Eu})$, gadolinium (Gd), terbium (Tb), dysprosium (Dy), holmium (Ho), erbium (Er), thulium (Tm), ytterbium (Yb) and lutetium (Lu). Yttrium (Y) and scandium $(\mathrm{Sc})$ are sometimes considered REE due to their

\footnotetext{
* Corresponding authors at: Institute of Geographic Sciences and Natural Resources Research, Chinese Academy of Sciences, 11A Datun Road, Chaoyang District, Beijing 100101, China. Tel.: +86 10 64889198; fax: +86 1064856504 (Y. Li). Tel.: +8610 64859781 (T. Liang).

E-mail addresses: yhli@igsnrr.ac.cn (Y. Li), liangt@igsnrr.ac.cn (T. Liang).
}

similar chemical and toxicological properties, and because these elements are often found in the same ore deposits (Thomas et al., 2014). REE are frequently divided into two subgroups: light REE (LREE) and heavy REE (HREE) based on their physical and chemical separabilities as well as their ion radius (Pang et al., 2002). The LREE have in common increasing unpaired electrons, from 0 to 7 , while the HREE are different from the LREE in that they have paired electrons (a clockwise and counter-clockwise spinning election). All the HREE adopt the hexagonal close-packed (hcp) crystal structure and all the LREE, with the exception of Sm, adopt the double $c$ axis hcp (dhcp) structure. Within each group, - chemical properties of the elements are very similar, with the result that they are always found together in mineral deposits. The LREE consists of the elements La, Ce, Pr, Nd, Pm, Sm and Eu, whereas the HREE com- 
prises the elements Gd, Tb, Dy, Ho, Er, Tm, Yb, Lu and Y. Pm, as one of the LREE, only occurs in trace quantities in nature as it has no long-lived or stable isotopes (Castor and Hedrick, 2006).

According to the British Geological Survey Database, the only countries known to be actively mining REE are China, Russia, India, Brazil and Malaysia. Among these countries, China has the largest REE production, accounting for more than $97 \%$ of the global supplies (BGS, 2011). REE are indispensable in many industries and technologies involving metallurgy, ceramics, magnets, petroleum, electronics, medical imagery, etc. (Castor and Hedrick, 2006; Hurst, 2010; Du and Graedel, 2013).

The global demand for REE is increasing annually and has led to the excessive exploitation of REE ores (Chen, 2011). Consequently, more REE are entering ecosystems through mining and processing as well as mine tailing wastes (Protano and Riccobono, 2002; Hu et al., 2006; Wang et al., 2008; Cai, 2012). REE in ores are generally by-products of iron, titanium, zircon, tin or sometimes $U$ extraction (BGS, 2011). Additionally, the environmental issues associated with REE production are caused not only by REE but also by impurity components, especially radionuclides and heavy metals, in the REE-bearing ores. For example, xenotime (a rare earth phosphate mineral, whose major component is yttrium orthophosphate) in Malaysian placer deposits typically contains $2 \% \mathrm{U}$ and $0.7 \%$ thorium. This was the main reason that the Malaysian processing industry failed and the plants were closed (BGS, 2011). The possible contaminants cause negative effects on aquatic and terrestrial organisms, as well as on humans. In some cases, they increase the mortality rates of aquatic and terrestrial organisms (Paul and Campbell, 2011; Rim et al., 2013).

The Baiyun Obo iron-REE-niobium deposit, located in Inner Mongolia, north China, is the world's largest REE deposit (BGS, 2011; Kanazawa and Kamitani, 2006; Wu, 2008), producing approximately $54 \%$ of the total global REE production (Li, 2008). According to China Daily refining one tonne of REE oxide can potentially produce $6 \times 10^{4} \mathrm{~m}^{3}$ of waste gas, $200 \mathrm{~m}^{3}$ of acidic water and 1.4 tonnes of radioactive waste. Intensive mining-refining operations and disposal of tailings piles in addition to litter governmental control have resulted in many crucial eco-environmental problems in Baiyun Obo district in the last few decades. Reports indicate that the contaminants associated with REE exploitation have been responsible for the pollution of local water, air and soil and the deterioration of the local grassland ecosystem (Hilsum, 2009; Meng et al., 2009; Guo et al., 2013; Wei et al., 2013; Xu et al., 2011).

Although there is no report of incidents of human REE poisoning through food consumption, concerns regarding potential effects of long-term exposure to REE on human health have been rising because REE can accumulate in blood, brain and bone after entering into the human body (Feng et al., 2000; Chen, 2005; Chen and Zhu, 2008; Rim et al., 2013). Previous epidemiological studies have identified the Baiyun Obo as one of the areas with the highest mortality rates due to malignant tumors in China (Zhang et al., 2001; Chen, 2005), suggesting that a combination of environmental, occupational and socio-economic factors may contribute to this health outcome. Unfortunately, despite the important eco-environmental deterioration caused by the mining activity, no biomonitoring study has been carried out in Baiyun Obo so far. This situation, together with the epidemiological finding mentioned above, were the basis of the present research focused on biomonitoring the exposure to pollutants related to REE production in a population in Baiyun Obo.

Urine is one of the most widely used and accepted mediums for biomonitoring environmental pollutants in occupational and environmental toxicology (Moon et al., 1999; Schroijen et al., 2008; Aguilera et al., 2010; Gil et al., 2011; Castano et al., 2012; Kitamura et al., 2012). Unlike hair, urine levels clearly reflect recent exposure. In addition, urine testing may substantially help in monitoring excessive exposure and appear to be suitable for use in prospective pilot studies as well as for identifying subgroups of population at increased risk in contaminated areas. In this study,

Table 1

Ceatinine adjusted urinary levels of REE, HMs and $\mathrm{U}$ in population living in the Baiyun Obo and the control area ( $\mu \mathrm{g} \mathrm{g}^{-1} \mathrm{creatinine}$ ).

\begin{tabular}{|c|c|c|c|c|c|c|c|c|c|c|c|c|c|}
\hline & \multicolumn{6}{|c|}{ Baiyun Obo $(N=128)$} & \multicolumn{6}{|c|}{ Control area $(N=12)$} & \multirow[t]{2}{*}{$p$-value } \\
\hline & AM & GM & P 10 & P 50 & P 90 & Max & AM & GM & P 10 & P 50 & P 90 & Max & \\
\hline La & 0.101 & 0.068 & 0.025 & 0.067 & 0.208 & 0.858 & 0.025 & 0.019 & 0.006 & 0.019 & 0.055 & 0.055 & 0.021 \\
\hline $\mathrm{Ce}$ & 0.138 & 0.083 & 0.020 & 0.078 & 0.361 & 0.796 & 0.020 & 0.016 & 0.007 & 0.017 & 0.031 & 0.037 & 0.009 \\
\hline $\operatorname{Pr}$ & 0.039 & 0.027 & 0.011 & 0.026 & 0.080 & 0.501 & 0.011 & 0.008 & 0.004 & 0.008 & 0.022 & 0.031 & 0.072 \\
\hline $\mathrm{Nd}$ & 0.181 & 0.135 & 0.057 & 0.134 & 0.369 & 2.307 & 0.044 & 0.035 & 0.020 & 0.047 & 0.066 & 0.088 & 0.034 \\
\hline $\mathrm{Sm}$ & 0.044 & 0.034 & 0.014 & 0.034 & 0.089 & 0.261 & 0.015 & 0.011 & 0.003 & 0.014 & 0.025 & 0.027 & 0.006 \\
\hline $\mathrm{Eu}$ & 0.020 & 0.016 & 0.007 & 0.017 & 0.038 & 0.067 & 0.007 & 0.005 & 0.003 & 0.005 & 0.010 & 0.025 & $<0.001$ \\
\hline Gd & 0.031 & 0.020 & 0.005 & 0.020 & 0.065 & 0.251 & 0.007 & 0.006 & 0.003 & 0.005 & 0.010 & 0.018 & 0.019 \\
\hline $\mathrm{Tb}$ & 0.018 & 0.013 & 0.003 & 0.013 & 0.040 & 0.133 & 0.007 & 0.006 & 0.003 & 0.006 & 0.014 & 0.020 & 0.032 \\
\hline Dy & 0.023 & 0.015 & 0.003 & 0.018 & 0.052 & 0.143 & 0.006 & 0.004 & 0.002 & 0.004 & 0.008 & 0.021 & 0.011 \\
\hline Ho & 0.167 & 0.122 & 0.036 & 0.150 & 0.326 & 0.777 & 0.081 & 0.049 & 0.012 & 0.083 & 0.163 & 0.186 & 0.016 \\
\hline $\mathrm{Er}$ & 0.013 & 0.010 & 0.003 & 0.009 & 0.025 & 0.075 & 0.004 & 0.003 & 0.002 & 0.003 & 0.006 & 0.006 & 0.003 \\
\hline $\mathrm{Tm}$ & 0.003 & 0.002 & 0.002 & 0.002 & 0.004 & 0.010 & 0.002 & 0.002 & 0.002 & 0.002 & 0.002 & 0.002 & 0.133 \\
\hline $\mathrm{Yb}$ & 0.008 & 0.005 & 0.003 & 0.006 & 0.015 & 0.115 & 0.004 & 0.003 & 0.002 & 0.003 & 0.008 & 0.009 & 0.225 \\
\hline Lu & 0.003 & 0.003 & 0.002 & 0.002 & 0.005 & 0.017 & 0.002 & 0.002 & 0.002 & 0.002 & 0.003 & 0.003 & 0.169 \\
\hline $\mathrm{Y}$ & 0.092 & 0.082 & 0.049 & 0.079 & 0.135 & 0.558 & 0.032 & 0.030 & 0.020 & 0.031 & 0.046 & 0.050 & $<0.001$ \\
\hline $\mathrm{Cr}$ & 2.885 & 2.739 & 1.787 & 2.812 & 3.967 & 6.149 & 1.224 & 1.142 & 0.725 & 1.135 & 1.824 & 2.348 & $<0.001$ \\
\hline Mn & 0.991 & 0.892 & 0.562 & 0.824 & 1.472 & 5.092 & 0.671 & 0.632 & 0.402 & 0.597 & 1.024 & 1.146 & 0.081 \\
\hline $\mathrm{Ni}$ & 5.943 & 5.041 & 2.401 & 5.443 & 10.079 & 17.693 & 3.765 & 3.283 & 1.810 & 3.604 & 5.864 & 5.948 & 0.035 \\
\hline $\mathrm{Cu}$ & 29.417 & 28.252 & 18.121 & 29.338 & 39.759 & 55.538 & 16.549 & 15.296 & 9.309 & 16.348 & 23.971 & 25.142 & $<0.001$ \\
\hline As & 27.832 & 24.925 & 14.099 & 25.106 & 41.146 & 126.088 & 13.497 & 12.161 & 6.473 & 10.639 & 20.991 & 27.103 & 0.002 \\
\hline $\mathrm{Cd}$ & 0.483 & 0.392 & 0.152 & 0.388 & 1.020 & 1.816 & 0.227 & 0.199 & 0.094 & 0.212 & 0.348 & 0.551 & 0.011 \\
\hline $\mathrm{Pb}$ & 1.650 & 1.250 & 0.517 & 1.318 & 3.024 & 10.001 & 0.723 & 0.460 & 0.103 & 0.687 & 1.525 & 1.853 & 0.014 \\
\hline $\mathrm{U}$ & 0.084 & 0.058 & 0.016 & 0.061 & 0.193 & 0.436 & 0.018 & 0.011 & 0.002 & 0.013 & 0.035 & 0.054 & 0.001 \\
\hline$\sum$ LREE & 0.523 & 0.403 & 0.197 & 0.368 & 1.125 & 3.453 & 0.121 & 0.106 & 0.048 & 0.127 & 0.187 & 0.196 & 0.005 \\
\hline$\sum$ HREE & 0.358 & 0.318 & 0.162 & 0.312 & 0.581 & 1.151 & 0.144 & 0.124 & 0.067 & 0.155 & 0.223 & 0.262 & $<0.001$ \\
\hline$\sum$ HMs & 69.201 & 65.688 & 43.489 & 67.090 & 94.163 & 171.399 & 36.357 & 34.388 & 22.200 & 34.714 & 50.584 & 55.931 & $<0.001$ \\
\hline
\end{tabular}

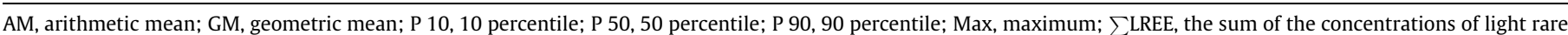

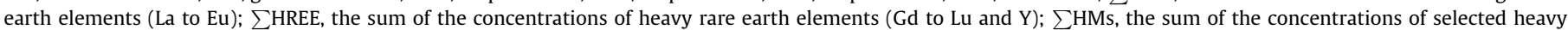
elements ( $\mathrm{Cr}, \mathrm{Mn}, \mathrm{Ni}, \mathrm{Cu}, \mathrm{As}, \mathrm{Cd}$ and $\mathrm{Pb})$. 
levels of 24 trace metals including 16 REE (La, Ce, Pr, Nd, Pm, Sm, $\mathrm{Eu}, \mathrm{Gd}, \mathrm{Tb}, \mathrm{Dy}, \mathrm{Ho}, \mathrm{Er}, \mathrm{Tm}, \mathrm{Yb}, \mathrm{Lu}, \mathrm{Y}), 7$ heavy metals (Cr, Mn, Ni, $\mathrm{Cu}, \mathrm{As}, \mathrm{Cd}$ and $\mathrm{Pb}$ ) and 1 radionuclide (U) have been measured in urine samples in a cohort of individuals living in Baiyun Obo. Given that age, gender and lifestyle are the major factors contributing to the inter-individual variation in these metals in urine (Aguilera et al., 2008), this study simultaneously identifies individual factors associated with levels of the metals. To the best of our knowledge, the current research represents the first scientific contribution reporting levels of three types of inorganic environmental pollutants (namely REE, radionuclide and heavy metals) in urine samples across an adult population. Hence this study provides systemic and basic information that may be useful for comparisons in future studies or addressing public and environmental health challenges in the areas where REE are mined and processed.

\section{Materials and methods}

\subsection{Study area}

The Baiyun Obo iron-REE-niobium deposit is located in the city of Baotou, in central Inner Mongolia Autonomous Region of north China, with north latitude from $41^{\circ} 39^{\prime}$ to $41^{\circ} 53^{\prime}$ and east longitude from $109^{\circ} 47^{\prime}$ to $109^{\circ} 04^{\prime}$. The location has a typical arid climate with annual average temperature and rainfall of $2.5^{\circ} \mathrm{C}$ and $250 \mathrm{~mm}$, respectively. The deposit consists of three main ore bodies (Main, East and West) lying along an east-west trending zone, with an area of $48 \mathrm{~km}^{2}$. The deposit is stratabound and hosted by mid-Proterozoic metasedimentary rocks of the Baiyun Obo Group, largely within a dolomite marble (Wu, 2008). Multiple mineralizing stages are evident in the deposit and over 170 minerals have been identified (BGS, 2011). REE in the deposit principally occur as monazite $\left[(\mathrm{Ce}, \mathrm{La}, \mathrm{Nd}, \mathrm{Th}) \mathrm{PO}_{4}\right]$ and bastnäsite $[(\mathrm{Ce}$, $\left.\mathrm{La})\left(\mathrm{CO}_{3}\right) \mathrm{F}\right]$, particularly enriched in LREE including $\mathrm{La}, \mathrm{Ce}, \mathrm{Pr}$ and Nd (Gao, 2009), which are extracted as a by-product of iron ore extraction. The deposit has been mined since 1957 and the current annual mineral production is as high as 11 million tonnes (Wei et al., 2013). An agricultural village (Wulanji 5th) situated in the same county about $200 \mathrm{~km}$ west of the Baiyun Obo deposit, where no contamination related to REE mining can be found, was selected as the control area (Supplementary Fig. 1). People living in the control area come from the same ethnic group and have similar diets and lifestyles to those from the Baiyun Obo.

\subsection{Sample collection and preparation}

In autumn 2010, a cross-sectional study was undertaken in Baoshan, a village from the Baiyun Obo mining area and Wulanji 5th, a village from the control area. Baoshan is at high risk of exposure to environmental pollution from REE mining activities; specifically, it is located downwind and less than $1.5 \mathrm{~km}$ away the Main orebody of the Baiyun Obo deposit. Trained interviewers visited the households of the target population to select the study subjects, perform interviews and collect urine samples. This is not a study of an occupationally exposed population but of a sample of the general adult population living in the area. In each village, we identified a random population sample stratified by sex and age (18-29 years vs. $30-59$ years vs. $60-69$ years), aiming at recruiting similar numbers from each group. The two village municipalities gave listings of all inhabitants sorted by address. Households, defined as those who lived at the same address, were used as the sampling unit. We numbered the households consecutively, and generated a random-number list. Households with a number matching the list were invited to participate and any household member older than 18 years was eligible. To guarantee a representative collection of urine samples, the enrollment criteria of the participants included: (i) be a volunteer; (ii) be an adult aged 18-69; (iii) has been living at his/her current address for at least 10 years; (iv) be non-occupational exposure to REE and heavy metals; (v) be able to adequately communicate with the interviewer and grant an interview and (vi) have no measurable functional or cognitive limitations. Within each village, recruitment was done by "knocking on doors" and interviewing those who met the inclusion criteria and agreed to participate, including providing a urine sample. For each address visited, where there were individuals who refused to participate in the study or were not home at the time of the visit, this was documented. Under the selection criteria, 145 apparently healthy individuals (133 from the Baiyun Obo and 12 from the control area) participated in this study after written informed consent. Approximately $20 \mathrm{ml}$ of morning urine from each fasting participant was collected in a $25 \mathrm{ml}$ metal-free polyethylene tubes (Nunc ${ }^{\mathrm{TM}}$, Roskilde, Denmark). Once collected, samples were kept at $4{ }^{\circ} \mathrm{C}$ until stored at $-20^{\circ} \mathrm{C}$ at the Baotou Environmental Monitoring Station (EMS). During their transfer from the Baotou EMS to the Beijing
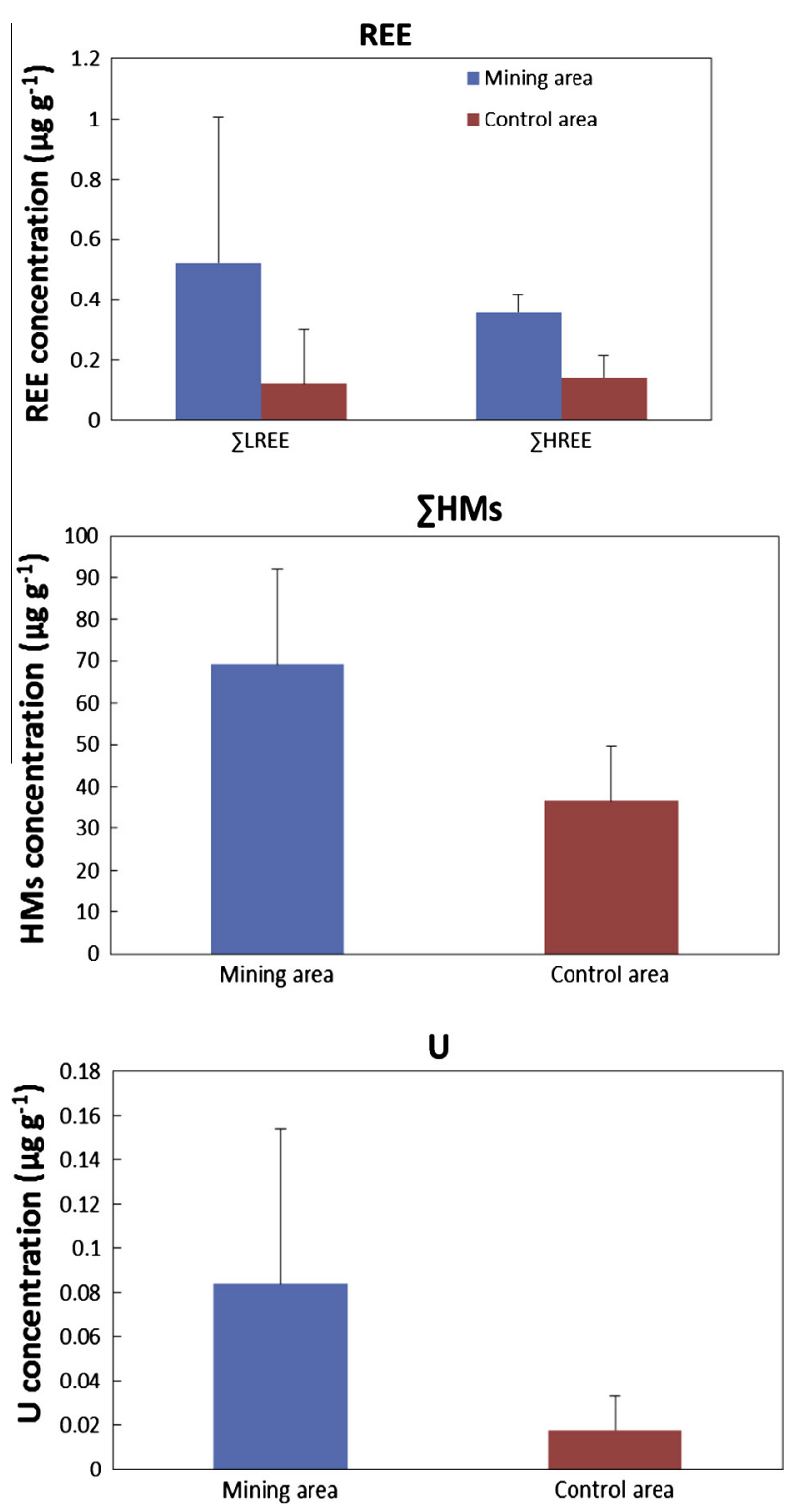

Fig. 1. Concentrations of REE, HMs and $U$ in morning urine in the Baiyun Obo and the control area (the indicate bars and errors represent means and their standard deviation, respectively). 
laboratory, the samples were kept frozen in insulated containers with ice packs. Following urine sample collection, face-to-face interviews were conducted with participants to collect information on socio-demographic characteristics and lifestyle habits.

All of the participants from the two communities were informed about the objectives of this study and agreed to collaborate, and the present study was approved by the bioethics committee of the Institute of Geographical Sciences and Natural Resource Research, Chinese Academy of Sciences.

\subsection{Analytical methods}

Samples were defrosted at $4{ }^{\circ} \mathrm{C}$ and divided in two aliquots, which were placed in acid precleaned polyethylene tubes (Nunc ${ }^{\mathrm{TM}}$, Roskilde, Denmark, and checked to be free from metal) pretreated with $5 \%$ nitric acid solution and rinsed twice with high-purity deionized water provided by a Milli-Q Plus filter apparatus (Millipore, Bedford, MA, USA). One aliquot was used for $\mathrm{La}, \mathrm{Ce}, \mathrm{Pr}, \mathrm{Nd}, \mathrm{Pm}, \mathrm{Sm}$, Eu, Gd, Tb, Dy, Ho, Er, Tm, Yb, Lu, Y, Cr, Mn, Ni, Cu, As, Cd, Pb and U determination, and the other for creatinine determination. The analytical procedures followed for the determination of urinary metals have been reported elsewhere (Cui et al., 2005; Kitamura et al., 2012). ELAN 9000 inductively coupled plasma mass spectrometry (PerkinElmer, Waltham, MA, USA) was used for all metal ion determination. For quality assurance and control, blank spikes, standard solutions (obtained from the National Center of Analysis and Testing for Nonferrous Metals and Electronic Material, China) and blind duplicates were used during analyses. The recoveries on spiked samples of the 25 metals ranged from $83 \%$ to $108 \%$ and the relative percentage differences were less than $11 \%$ in duplicate samples. The limits of detection (LOD) for the metals were $0.002-$ $0.017 \mu \mathrm{g} \mathrm{L}^{-1}$, which were determined as three times the standard deviation from seven blank solutions.

Urine creatinine was measured on a Reflotron ${ }^{\circledR}$ Plus chemistry analyzer according to the manufacturer's instructions. Briefly, urine creatinine was detected using a series of coupled reactions, in which creatinine was first converted to N-methylhydantoin and ammonia by creatinine iminohydrolyse; the final step of the cascade was the conversion of generated hydrogen peroxide to a detectable product using hydrogen peroxidase and tetramethyl blue as a substrate.

\subsection{Statistical analysis}

Metal concentrations in urine were adjusted for creatinine to reduce inter-individual variation of urinary measurements (Moon et al., 1999; Aguilera et al., 2008). The World Health Organisation (WHO) has developed guidelines which stipulate that urine samples with creatinine concentrations below $30 \mathrm{mg} \mathrm{dL}^{-1}$ or above $300 \mathrm{mg} \mathrm{dL}^{-1}$ are regarded as either too diluted or too concentrated (WHO, 1996). After discarding these levels, the final number of participants in this study was 140 (128 from the Baiyun Obo and 12 from the control area). Concentrations below the LOD were replaced by $\mathrm{LOD} / 2$. Log-transformed metal concentrations were used to normalize their distribution.

Differences in concentration levels of the metals as well as the potential influence of confounders (age, gender, educational level, tobacco, alcohol) on the levels were ascertained by using the Student's $t$-test or ANOVA. The magnitude of the urinary REE's correlation with urinary $U$ and urinary heavy metal levels were assessed by using the Spearman rank correlation test. All statistical analyses were performed using Statistica 6.0 for Windows (StatSoft, Inc., Tulsa, USA).

\section{Results and discussion}

\subsection{Descriptive statistics of the metal concentrations}

The descriptive statistics for REE, heavy metals and $U$ in the morning urine samples from Baiyun Obo and the control area are presented in Table 1. Using a normal deviation test, concentrations of all the REE as well as $\sum$ LREE and $\sum$ HREE were non-normally distributed. Except for concentration of $\mathrm{Cu}$, all the other heavy metals were also non-normally distributed, while $\sum$ HMs were normally distributed. Concentration of $U$ was non-normally distributed.

It can be seen in Table 1 that the mean concentrations of all REE, heavy metals and $U$ in morning urine samples from Baiyun Obo

Table 2

Comparison of the elemental concentrations from Baiyun Obo with other published data.

\begin{tabular}{|c|c|c|c|c|c|c|c|}
\hline & \multirow{2}{*}{\multicolumn{2}{|c|}{$\begin{array}{l}\text { Baiyun Obo, China } \\
\text { Our study }\end{array}$}} & \multirow{3}{*}{$\begin{array}{l}\text { Ria of Huelva, Spain } \\
\text { Aguilera et al. (2008) } \\
\text { GM }\left(\mu \mathrm{g} \mathrm{g}^{-1}\right)\end{array}$} & \multirow{3}{*}{$\begin{array}{l}\text { Germany } \\
\text { Heitland and Koster (2006) } \\
\text { GM }\left(\mu \mathrm{g} \mathrm{g}^{-1}\right) \\
\end{array}$} & \multirow{3}{*}{$\begin{array}{l}\text { Buxton, UK } \\
\text { Morton et al. (2014) } \\
\left.\text { Median ( } \mu \mathrm{g} \mathrm{L}^{-1}\right) \\
\end{array}$} & \multirow{3}{*}{$\begin{array}{l}\text { Tianjin, China } \\
\text { Xie et al. (2012) } \\
\left.\text { Median ( } \mu \mathrm{g} \mathrm{L}^{-1}\right)\end{array}$} & \multirow[t]{3}{*}{ Chengdu, China } \\
\hline & & & & & & & \\
\hline & $\mathrm{GM}\left(\mu \mathrm{g} \mathrm{g}^{-1}\right)$ & Median $\left(\mu \mathrm{g} \mathrm{L}^{-1}\right)$ & & & & & \\
\hline La & 0.068 & 0.079 & & & 0.001 & 0.052 & 0.035 \\
\hline $\mathrm{Ce}$ & 0.083 & 0.089 & & & $<\operatorname{LOD}(0.005)$ & 0.075 & 0.038 \\
\hline $\mathrm{Pr}$ & 0.027 & 0.030 & & & $<\operatorname{LOD}(0.003)$ & 0.010 & 0.006 \\
\hline $\mathrm{Nd}$ & 0.135 & 0.153 & & & $<\operatorname{LOD}(0.007)$ & 0.034 & 0.019 \\
\hline $\mathrm{Sm}$ & 0.034 & 0.040 & & & $<\operatorname{LOD}(0.006)$ & 0.099 & 0.130 \\
\hline $\mathrm{Eu}$ & 0.016 & 0.019 & & & $<\operatorname{LOD}(0.014)$ & 0.008 & 0.008 \\
\hline Gd & 0.020 & 0.024 & & & $<\operatorname{LOD}(0.009)$ & & \\
\hline $\mathrm{Tb}$ & 0.013 & 0.015 & & & $<\operatorname{LOD}(0.003)$ & & \\
\hline Dy & 0.015 & 0.020 & & & $<\operatorname{LOD}(0.005)$ & & \\
\hline Ho & 0.122 & 0.171 & & & $<\operatorname{LOD}(0.0001)$ & & \\
\hline $\mathrm{Er}$ & 0.01 & 0.011 & & & $<\operatorname{LOD}(0.0003)$ & & \\
\hline $\mathrm{Tm}$ & 0.002 & 0.002 & & & $<\operatorname{LOD}(0.0002)$ & & \\
\hline $\mathrm{Yb}$ & 0.005 & 0.007 & & & $<\operatorname{LOD}(0.0003)$ & & \\
\hline $\mathrm{Lu}$ & 0.003 & 0.002 & & & $<\operatorname{LOD}(0.0001)$ & & \\
\hline $\mathrm{Y}$ & 0.082 & 0.094 & & & $<\operatorname{LOD}(0.059)$ & & \\
\hline $\mathrm{Cr}$ & 1.787 & 3.338 & 0.37 & 0.12 & 0.35 & & \\
\hline Mn & 0.562 & 0.978 & & 0.06 & $<\operatorname{LOD}(0.092)$ & & \\
\hline $\mathrm{Ni}$ & 2.401 & 6.191 & 1.15 & 0.29 & 1.99 & & \\
\hline $\mathrm{Cu}$ & 18.121 & 33.372 & 8.39 & 5 & 8.75 & & \\
\hline As & 14.099 & 29.800 & 1.44 & 12 & 10.48 & & \\
\hline $\mathrm{Cd}$ & 0.152 & 0.460 & 0.49 & 0.16 & 0.13 & & \\
\hline $\mathrm{Pb}$ & 0.517 & 1.564 & & 0.5 & 0.47 & & \\
\hline $\mathrm{U}$ & 0.016 & 0.072 & & 0.003 & & & \\
\hline
\end{tabular}


Table 3

Correlation coefficients between metals and selected factors.

\begin{tabular}{|c|c|c|c|c|c|c|c|c|c|c|c|c|c|c|c|}
\hline & Gender & Age & EL & $\mathrm{AI}$ & $\mathrm{SH}$ & $\mathrm{Cr}$ & Mn & $\mathrm{Ni}$ & $\mathrm{Cu}$ & As & $\mathrm{Cd}$ & $\mathrm{Pb}$ & $\mathrm{U}$ & ¿LREE & $\sum$ HREE \\
\hline Age & 0.12 & & & & & & & & & & & & & & \\
\hline $\mathrm{EL}^{\mathrm{a}}$ & -0.06 & $-0.53^{*}$ & & & & & & & & & & & & & \\
\hline $\mathrm{AI}^{\mathrm{b}}$ & $-0.40^{*}$ & -0.03 & $0.18^{*}$ & & & & & & & & & & & & \\
\hline $\mathrm{SH}^{\mathrm{c}}$ & $-0.44^{*}$ & $0.21^{*}$ & -0.04 & $0.42^{*}$ & & & & & & & & & & & \\
\hline $\mathrm{Cr}$ & -0.14 & -0.13 & 0.12 & 0.14 & 0.14 & & & & & & & & & & \\
\hline Mn & 0.13 & -0.15 & 0.15 & -0.12 & -0.14 & 0.02 & & & & & & & & & \\
\hline $\mathrm{Ni}$ & 0.05 & $-0.23^{*}$ & $0.24^{*}$ & 0.01 & 0.03 & $0.50^{*}$ & $0.19^{*}$ & & & & & & & & \\
\hline $\mathrm{Cu}$ & -0.09 & -0.08 & 0.00 & 0.09 & 0.04 & $0.27^{*}$ & -0.02 & $0.30^{*}$ & & & & & & & \\
\hline As & -0.06 & $-0.20^{*}$ & 0.10 & 0.09 & -0.01 & $0.33^{*}$ & 0.13 & $0.38^{*}$ & $0.35^{*}$ & & & & & & \\
\hline $\mathrm{Cd}$ & $-0.27^{*}$ & 0.00 & 0.14 & $0.32^{*}$ & $0.35^{*}$ & $0.46^{*}$ & 0.15 & $0.40^{*}$ & $0.29^{*}$ & $0.35^{*}$ & & & & & \\
\hline $\mathrm{Pb}$ & $-0.28^{*}$ & $-0.24^{*}$ & $0.19^{*}$ & $0.18^{*}$ & $0.20^{*}$ & $0.35^{*}$ & $0.23^{*}$ & $0.34^{*}$ & $0.22^{*}$ & $0.39^{*}$ & $0.49^{*}$ & & & & \\
\hline $\mathrm{U}$ & -0.07 & -0.03 & $0.21^{*}$ & 0.12 & -0.14 & 0.08 & $0.32^{*}$ & 0.14 & -0.03 & $0.18^{*}$ & 0.16 & $0.22^{*}$ & & & \\
\hline$\sum$ LREE & 0.02 & -0.02 & 0.14 & 0.04 & 0.06 & 0.07 & $0.51^{*}$ & $0.24^{*}$ & 0.09 & 0.17 & $0.42^{*}$ & $0.37^{*}$ & 0.15 & & \\
\hline$\sum$ HREE & 0.02 & -0.11 & 0.09 & 0.01 & -0.08 & $0.19^{*}$ & $0.42^{*}$ & $0.47^{*}$ & $0.56^{*}$ & $0.31^{*}$ & $0.18^{*}$ & $0.24^{*}$ & $0.24^{*}$ & $0.47^{*}$ & \\
\hline$\sum \mathrm{HMs}$ & -0.20 & $-0.20^{*}$ & 0.12 & 0.11 & 0.03 & $0.46^{*}$ & 0.15 & $0.57^{*}$ & $0.67^{*}$ & $0.91^{*}$ & $0.47^{*}$ & $0.48^{*}$ & 0.16 & $0.23^{*}$ & $0.52^{*}$ \\
\hline
\end{tabular}

The sample size is 128

Denotes correlation significant at $p<0.05$ level.

a EL, educational level.

b AI, alcohol intake.

c $\mathrm{SH}$, smoking habit.

were higher than those from the control area. The Student's $t$-test showed that the mean concentrations of the metals were significantly different between the two areas $(p<0.05)$, except for $\mathrm{Pr}$, $\mathrm{Tm}, \mathrm{Yb}, \mathrm{Lu}$ and $\mathrm{Mn}$. The results in both Table 1 and Fig. 1 show that $\sum$ LREE, $\sum$ HREE and $\sum$ HMs from Baiyun Obo were strikingly higher than those from the control area $(p<0.01)$. In the mining area, $\sum$ LREE was higher than $\sum$ HREE. This might indicate that the environment in the mining area has been significantly influenced and the pollution of REE is mainly from LREE.

Table 2 shows a comparison of our results with several earlier reports on the elements in human urine. For most elements, there is a trend that concentrations in Baiyun Obo are much higher than those from other places. Both the results of Tables 1 and 2 show this mining area might be exposed to high concentrations of REE, HMs and radionuclide, which provides evidence that the environment in this mining area has been significantly polluted by rare earth mining processes.

In order to evaluate the relationship between REE and other trace metals, the correlations between different metals are presented in Table 3. Correlation coefficients between most of the metals are positive and statistically significant. The coefficients of $\sum$ HREE with $\sum$ HMs and U concentration ( $\sum$ HREE- $\sum$ HMs: 0.52;

Table 4

Levels of REE, HMs and $U$ in urine of population living in Baiyun Obo after adjusted for factors selected by multiple linear regression ( $\mu g \mathrm{~g}^{-1}$ creatinine).

\begin{tabular}{|c|c|c|c|c|c|c|c|c|}
\hline & \multicolumn{3}{|c|}{ Baiyun Obo $(N=128)$} & \multicolumn{3}{|c|}{ Control area $(N=12)$} & \multicolumn{2}{|l|}{$p$-Value } \\
\hline & Mean & Mean-adj $^{\mathrm{a}}$ & Factors & Mean & Mean-adj & Factors & $p$ & $p$-Adj ${ }^{\mathrm{b}}$ \\
\hline $\mathrm{La}$ & 0.101 & 0.098 & Age Gender $\mathrm{SH}^{\mathrm{c}} \mathrm{AI}^{\mathrm{d}}$ & 0.025 & 0.019 & Age Gender SH AI & 0.021 & 0.040 \\
\hline $\mathrm{Ce}$ & 0.138 & 0.134 & Age Gender SH AI & 0.020 & 0.016 & Age Gender SH AI & 0.009 & 0.017 \\
\hline $\operatorname{Pr}$ & 0.039 & 0.037 & Age Gender SH AI & 0.011 & 0.008 & Age Gender SH AI & 0.072 & 0.132 \\
\hline $\mathrm{Nd}$ & 0.181 & 0.181 & Age Gender SH AI & 0.044 & 0.035 & Age Gender SH AI & 0.034 & 0.041 \\
\hline $\mathrm{Sm}$ & 0.044 & 0.043 & Age Gender SH AI EL & 0.015 & 0.011 & Age Gender SH AI & 0.006 & 0.012 \\
\hline $\mathrm{Eu}$ & 0.020 & 0.021 & Age Gender SH AI EL & 0.007 & 0.005 & Age Gender SH AI & $<0.001$ & $<0.001$ \\
\hline Gd & 0.031 & 0.030 & Age Gender SH AI EL & 0.007 & 0.006 & Age Gender SH AI EL & 0.019 & 0.032 \\
\hline $\mathrm{Tb}$ & 0.018 & 0.019 & Age Gender SH AI & 0.007 & 0.006 & Age Gender SH AI & 0.032 & 0.021 \\
\hline Dy & 0.023 & 0.022 & Age Gender SH AI & 0.006 & 0.004 & Age Gender SH AI EL & 0.011 & 0.018 \\
\hline Ho & 0.167 & 0.174 & Age Gender SH AI & 0.081 & 0.049 & Age Gender SH AI & 0.016 & 0.006 \\
\hline $\mathrm{Er}$ & 0.013 & 0.013 & Age Gender SH AI EL & 0.004 & 0.003 & Age Gender SH AI & 0.003 & 0.008 \\
\hline $\mathrm{Tm}$ & 0.003 & 0.003 & Age Gender SH AI EL & 0.002 & 0.002 & Age Gender SH AI & 0.133 & 0.281 \\
\hline $\mathrm{Yb}$ & 0.008 & 0.008 & Age Gender SH AI EL & 0.004 & 0.003 & Age Gender SH AI EL & 0.225 & 0.235 \\
\hline $\mathrm{Lu}$ & 0.003 & 0.003 & Age Gender SH AI EL & 0.002 & 0.002 & Age Gender SH AI EL & 0.169 & 0.204 \\
\hline $\mathrm{Y}$ & 0.092 & 0.091 & Age Gender SH AI EL & 0.032 & 0.030 & Age Gender SH AI & $<0.001$ & 0.002 \\
\hline $\mathrm{Cr}$ & 2.885 & 2.950 & Age Gender SH AI & 1.224 & 1.142 & Age Gender SH AI EL & $<0.001$ & $<0.001$ \\
\hline $\mathrm{Mn}$ & 0.991 & 0.967 & Age Gender SH AI EL & 0.671 & 0.632 & Age Gender SH AI & 0.081 & 0.154 \\
\hline $\mathrm{Ni}$ & 5.943 & 6.028 & Age Gender SH AI EL & 3.765 & 3.283 & Age Gender SH AI EL & 0.035 & 0.022 \\
\hline $\mathrm{Cu}$ & 29.417 & 29.994 & Age Gender SH AI & 16.549 & 15.296 & Age Gender SH AI EL & $<0.001$ & $<0.001$ \\
\hline As & 27.832 & 28.640 & Age Gender SH AI & 13.497 & 12.161 & Age Gender SH AI EL & 0.002 & 0.001 \\
\hline $\mathrm{Cd}$ & 0.483 & 0.475 & Age Gender SH AI EL & 0.227 & 0.199 & Age Gender SH AI EL & 0.011 & 0.013 \\
\hline $\mathrm{Pb}$ & 1.650 & 1.751 & Age Gender SH AI & 0.723 & 0.460 & Age Gender SH AI EL & 0.014 & 0.001 \\
\hline $\mathrm{U}$ & 0.084 & 0.083 & SH Gender EL Age & 0.018 & 0.011 & Age Gender SH AI & 0.001 & 0.002 \\
\hline$\sum$ LREE & 0.523 & 0.514 & Age Gender SH AI & 0.121 & 0.106 & Age Gender SH AI & 0.005 & 0.010 \\
\hline$\sum$ HREE & 0.358 & 0.363 & Age Gender SH AI EL & 0.144 & 0.124 & Age Gender SH AI & $<0.001$ & $<0.001$ \\
\hline$\sum H M s$ & 69.201 & 70.805 & Age Gender SH AI & 36.357 & 34.388 & Age Gender SH AI EL & $<0.001$ & $<0.001$ \\
\hline
\end{tabular}

\footnotetext{
a Mean-adj, mean after correction for confounders and covariates.

b $p$-Adj, adjusted $p$ value.

c $\mathrm{SH}$, smoking habit.

d AI, alcohol intake.

e EL, educational level.
} 
$\sum$ HREE-U: 0.24$)$ are positive and statistically observable; the coefficient between $\sum$ LREE and $\sum$ HMs ( $\sum$ LREE- $\sum$ HMs: 0.23 ) is also positive and significant. The observed remarkable coefficients of REE with HMs and U suggest a close relationship among these metals. In addition to REE pollution, heavy metal and $U$ pollution are also serious outcome of REE mining and processing. The results confirm that HMs and $U$ are generally by-products of REE production.

By ingestion, inhalation, dermal contact and the food chain, REE, HMs and radionuclide can enter human body. The pollutants can be accumulated in blood, brain and bone (Feng et al., 2000; Chen, 2005; Chen and Zhu, 2008; Rim et al., 2013). Net element accumulation is a complex result of the physiological processes inside the organism (Ardestani et al., 2014), kinetics and half-life of the elements may also influence the levels. After entering the human body, metals are detoxified either via excretion or via storage in soluble or insoluble forms or in a special organ to be taken away from interaction with their target sites and to prevent diffusion into tissues and interference with biochemical reactions. Metals can accumulate in the target organs of infection (Rainbow, 2007).

Table 5

Associations among concentrations of metals in urine (geometric means in $\mu \mathrm{g} \mathrm{g}^{-1}$ creatinine) and several categorical variables in Baiyun Obo.

\begin{tabular}{|c|c|c|c|c|c|c|c|c|c|c|c|c|c|c|c|c|}
\hline Variables & $N(\%)$ & \multicolumn{2}{|c|}{$\sum$ LREE } & \multicolumn{2}{|c|}{$\sum$ HREE } & $\mathrm{Cr}$ & Mn & \multicolumn{2}{|l|}{$\mathrm{Ni}$} & $\mathrm{Cu}$ & \multicolumn{2}{|l|}{ As } & $\mathrm{Cd}$ & \multicolumn{2}{|c|}{$\mathrm{Pb}$} & $\mathrm{U}$ \\
\hline \multicolumn{17}{|l|}{ Gender } \\
\hline Male & $61(47.7)$ & \multicolumn{2}{|c|}{0.413} & \multicolumn{2}{|l|}{0.324} & 2.931 & 0.847 & \multicolumn{2}{|c|}{5.048} & 29.541 & \multicolumn{2}{|c|}{25.924} & 0.479 & \multicolumn{2}{|c|}{1.567} & 0.064 \\
\hline Female & $67(52.3)$ & \multicolumn{2}{|c|}{0.394} & 0.312 & & 2.575 & 0.935 & 5.0 & & 27.128 & 24. & & 0.327 & & 18 & 0.052 \\
\hline$p$-Value & & & & 0.629 & & 0.012 & 0.445 & 0.8 & & 0.053 & & & 0.003 & & 01 & 0.626 \\
\hline$p$-Adj ${ }^{\mathrm{a}}$ & & & & 0.400 & & 0.157 & 0.533 & 0.3 & & 0.143 & & & 0.291 & & 44 & 0.171 \\
\hline Age & & & & & & & & & & & & & & & & \\
\hline $18-29$ & 34 (26.6) & & & 0.356 & & 3.071 & 0.974 & 5.9 & & 29.991 & 28. & & 0.375 & & 581 & 0.065 \\
\hline $30-59$ & 55 (43.0) & & & 0.316 & & 2.705 & 0.831 & 5.5 & & 27.740 & 25. & & 0.434 & & 326 & 0.059 \\
\hline $60-69$ & $39(30.4)$ & & & 0.290 & & 2.524 & 0.912 & 3.8 & & 27.520 & 21. & & 0.353 & & 388 & 0.051 \\
\hline$p$-Value & & & & 0.463 & & 0.025 & 0.133 & 0.0 & & 0.338 & & & 0.421 & & 09 & 0.991 \\
\hline p-Adj & & & & 0.976 & & 0.060 & 0.023 & 0.0 & & 0.393 & & & 0.776 & & 32 & 0.399 \\
\hline Educational level & & & & & & & & & & & & & & & & \\
\hline Primary education & $38(29.7)$ & & & 0.290 & & 2.674 & 0.798 & 4.1 & & 27.917 & 22. & & 0.320 & & 916 & 0.039 \\
\hline Secondary education & $75(58.6)$ & & & 0.328 & & 2.680 & 0.928 & 5.2 & & 28.493 & 25. & & 0.432 & & 413 & 0.068 \\
\hline University degree & $15(11.7)$ & & & 0.342 & & 3.247 & 0.971 & 6.9 & & 27.908 & 26. & & 0.404 & & 485 & 0.067 \\
\hline$p$-Value & & & & 0.225 & & 0.127 & 0.200 & 0.0 & & 0.889 & & & 0.189 & & 27 & 0.245 \\
\hline p-Adj & & & & 0.438 & & 0.118 & 0.034 & 0.2 & & 0.735 & & & 0.413 & & 788 & 0.248 \\
\hline Alcohol intake & & & & & & & & & & & & & & & & \\
\hline Non-drinkers & $82(64.1)$ & & & 0.323 & & 2.682 & 0.913 & 5.0 & & 27.847 & 24. & & 0.342 & & 137 & 0.055 \\
\hline Drinkers & $46(35.9)$ & & & 0.309 & & 2.846 & 0.856 & 4.9 & & 28.989 & 25. & & 0.499 & & 479 & 0.063 \\
\hline$p$-Value & & & & 0.997 & & 0.247 & 0.863 & 0.6 & & 0.239 & & & 0.006 & & 09 & 0.593 \\
\hline p-Adj & & & & 0.891 & & 0.736 & 0.863 & 0.7 & & 0.589 & & & 0.461 & & 745 & 0.386 \\
\hline Smoking habit & & & & & & & & & & & & & & & & \\
\hline Never-smokers & $87(68.0)$ & & & 0.331 & & 2.658 & 0.909 & 4.9 & & 28.221 & 25. & & 0.335 & & 123 & 0.064 \\
\hline Current \& ex-smokers & $41(32.0)$ & & & 0.293 & & 2.922 & 0.857 & 5.2 & & 28.320 & 24. & & 0.548 & & 569 & 0.047 \\
\hline$p$-Value & & & & 0.330 & & 0.086 & 0.946 & 0.3 & & 0.696 & & & $<0.001$ & & 01 & 0.042 \\
\hline$p$-Adj & & & & 0.292 & & 0.156 & 0.933 & 0.0 & & 0.755 & & & 0.009 & & 17 & 0.005 \\
\hline Variables & $N(\%)$ & $\mathrm{La}$ & $\mathrm{Ce}$ & $\operatorname{Pr}$ & $\mathrm{Nd}$ & $\mathrm{Sm}$ & $\mathrm{Eu}$ & Gd & $\mathrm{Tb}$ & Dy & Ho & $\mathrm{Er}$ & $\mathrm{Tm}$ & $\mathrm{Yb}$ & Lu & $\mathrm{Y}$ \\
\hline Gender & & & & & & & & & & & & & & & & \\
\hline Male & $61(47.7)$ & 0.071 & 0.082 & 0.027 & 0.139 & 0.034 & 0.016 & 0.018 & 0.013 & 0.014 & 0.128 & 0.010 & 0.002 & 0.005 & 0.003 & 0.082 \\
\hline Female & $67(52.3)$ & 0.066 & 0.084 & 0.028 & 0.131 & 0.033 & 0.017 & 0.021 & 0.013 & 0.015 & 0.117 & 0.010 & 0.002 & 0.006 & 0.003 & 0.081 \\
\hline$p$-Value & & 0.885 & 0.742 & 0.842 & 0.377 & 0.948 & 0.983 & 0.392 & 0.717 & 0.670 & 0.298 & 0.458 & 0.449 & 0.132 & 0.079 & 0.856 \\
\hline$p$-Adj & & 0.626 & 0.788 & 0.867 & 0.800 & 0.765 & 0.888 & 0.672 & 0.883 & 0.583 & 0.079 & 0.827 & 0.106 & 0.307 & 0.046 & 0.750 \\
\hline Age & & & & & & & & & & & & & & & & \\
\hline $18-29$ & $34(26.6)$ & 0.065 & 0.076 & 0.026 & 0.145 & 0.034 & 0.020 & 0.021 & 0.015 & 0.019 & 0.144 & 0.010 & 0.003 & 0.007 & 0.003 & 0.089 \\
\hline $30-59$ & $55(43.0)$ & 0.072 & 0.086 & 0.027 & 0.138 & 0.037 & 0.017 & 0.020 & 0.015 & 0.015 & 0.117 & 0.010 & 0.002 & 0.005 & 0.003 & 0.079 \\
\hline 60-69 & $39(30.4)$ & 0.066 & 0.086 & 0.029 & 0.122 & 0.029 & 0.014 & 0.018 & 0.009 & 0.012 & 0.112 & 0.010 & 0.002 & 0.005 & 0.003 & 0.079 \\
\hline$p$-Value & & 0.317 & 0.326 & 0.617 & 0.908 & 0.756 & 0.062 & 0.987 & 0.026 & 0.384 & 0.341 & 0.914 & 0.642 & 0.266 & 0.268 & 0.499 \\
\hline$p$-Adj & & 0.433 & 0.363 & 0.670 & 0.970 & 0.688 & 0.608 & 0.733 & 0.095 & 0.360 & 0.484 & 0.564 & 0.440 & 0.514 & 0.360 & 0.279 \\
\hline Educational level & & & & & & & & & & & & & & & & \\
\hline Primary education & $38(29.7)$ & 0.058 & 0.078 & 0.027 & 0.121 & 0.026 & 0.012 & 0.017 & 0.011 & 0.012 & 0.124 & 0.008 & 0.002 & 0.005 & 0.002 & 0.072 \\
\hline Secondary education & $75(58.6)$ & 0.077 & 0.086 & 0.028 & 0.142 & 0.036 & 0.018 & 0.019 & 0.013 & 0.016 & 0.120 & 0.011 & 0.002 & 0.006 & 0.003 & 0.087 \\
\hline University degree & $15(11.7)$ & 0.056 & 0.081 & 0.027 & 0.139 & 0.042 & 0.024 & 0.028 & 0.015 & 0.016 & 0.126 & 0.010 & 0.003 & 0.006 & 0.003 & 0.085 \\
\hline$p$-Value & & 0.695 & 0.979 & 0.838 & 0.813 & 0.036 & 0.003 & 0.288 & 0.201 & 0.372 & 0.886 & 0.136 & 0.236 & 0.165 & 0.086 & 0.237 \\
\hline$p$-Adj & & 0.664 & 0.859 & 0.783 & 0.929 & 0.032 & 0.026 & 0.109 & 0.638 & 0.786 & 0.881 & 0.131 & 0.342 & 0.309 & 0.163 & 0.085 \\
\hline Alcohol intake & & & & & & & & & & & & & & & & \\
\hline Non-drinkers & $82(64.1)$ & 0.068 & 0.082 & 0.028 & 0.136 & 0.032 & 0.017 & 0.022 & 0.013 & 0.013 & 0.130 & 0.009 & 0.002 & 0.006 & 0.003 & 0.083 \\
\hline Drinkers & 46 (35.9) & 0.069 & 0.084 & 0.027 & 0.133 & 0.037 & 0.016 & 0.016 & 0.012 & 0.018 & 0.109 & 0.011 & 0.003 & 0.005 & 0.003 & 0.080 \\
\hline$p$-Value & & 0.912 & 0.992 & 0.591 & 0.463 & 0.945 & 0.565 & 0.369 & 0.923 & 0.126 & 0.825 & 0.354 & 0.269 & 0.188 & 0.201 & 0.728 \\
\hline$p$-Adj & & 0.709 & 0.492 & 0.780 & 0.925 & 0.628 & 0.263 & 0.401 & 0.577 & 0.245 & 0.709 & 0.767 & 0.303 & 0.320 & 0.162 & 0.440 \\
\hline Smoking habit & & & & & & & & & & & & & & & & \\
\hline Never-smokers & $87(68.0)$ & 0.067 & 0.075 & 0.027 & 0.134 & 0.032 & 0.017 & 0.020 & 0.014 & 0.014 & 0.138 & 0.009 & 0.002 & 0.006 & 0.003 & 0.080 \\
\hline Current and ex-smokers & $41(32.0)$ & 0.072 & 0.102 & 0.028 & 0.137 & 0.036 & 0.015 & 0.018 & 0.011 & 0.016 & 0.093 & 0.012 & 0.003 & 0.005 & 0.003 & 0.086 \\
\hline$p$-Value & & 0.202 & 0.044 & 0.344 & 0.226 & 0.676 & 0.576 & 0.582 & 0.977 & 0.401 & 0.073 & 0.312 & 0.483 & 0.261 & 0.774 & 0.477 \\
\hline$p$-Adj & & 0.202 & 0.057 & 0.552 & 0.375 & 0.502 & 0.917 & 0.984 & 0.651 & 0.489 & 0.020 & 0.587 & 0.321 & 0.976 & 0.058 & 0.339 \\
\hline
\end{tabular}

${ }^{a} p$-Adj, $p$ value after adjusted for other factors.

b Alcohol intake is classified as non-drinking ( $0-0.5$ unit per week) and drinking ( $>0.5$ unit per week). 1 unit is defined as 1 bottle of beer, 1 glass of wine or 1 glass of aquavit. 
The half-life range differences of REEs affect their amounts. For example, the longest-lived isotope of promethium has a half-life of 17.7 years, so the element exists in nature in only negligible amounts (Belli et al., 2007).

Raw data were adjusted by regression analyses for some prespecified, literature-based confounders (Vermeulen et al., 1996; Ukkola et al., 2001; Zitzmann and Nieschlag, 2001) and for covariates reported to have an influence on element levels in urine. Confounders (gender, age, alcohol intake and smoking habit) were kept in the models, non-regardless their significance. Covariates (education level), however, were only kept in the model when their effects on the element concentration were observable. Table 4 gives an overview of different elements and their confounding factors for urine samples that are taken into account (Vrijens et al., 2014). The correction causes some variations on p-values. However, it does not influence the significant differences, mean concentrations of the elements are still significantly different between the
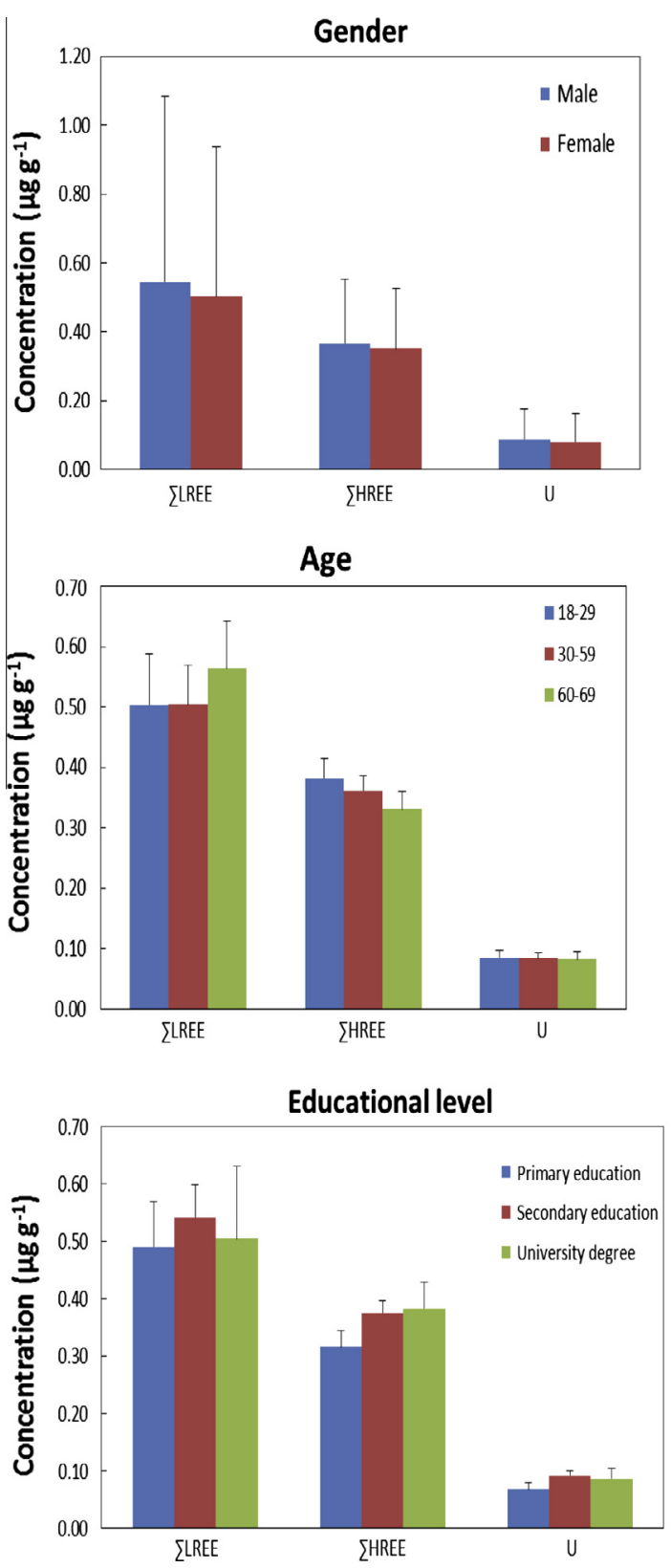

two areas ( $p<0.05$ ), except for Pr, Tm, Yb, Lu and Mn, which is similar to the unadjusted results.

\subsection{Individual factors influencing metal levels}

Inter-individual variation in levels of metals in urine is the result of multi-factorial comprehensive action. This study simultaneously identified individual factors associated with levels of metals in urine. The selected factors studied are gender, age, educational level, alcohol and smoking habits. The results of Student's $t$-tests or ANOVA for the variations are presented in Table 5. The statistics for REE are represented by $\sum$ LREE and $\sum$ HREE. All the 128 samples come from the mining area.

\subsubsection{Variation in metal concentration by gender}

There are differences in personal characteristics as well as exposure characteristics (life style, environmental factors) between males and females, so the harmful effects of the metals on males

A
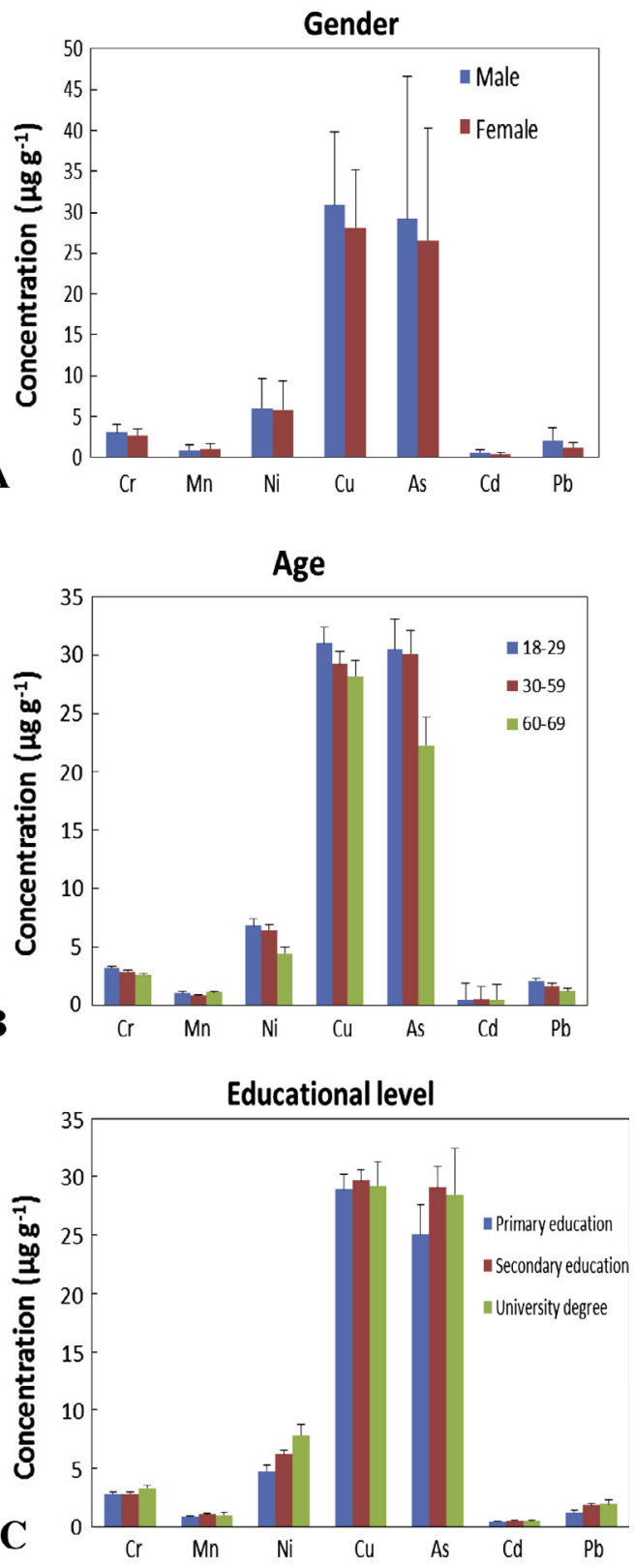

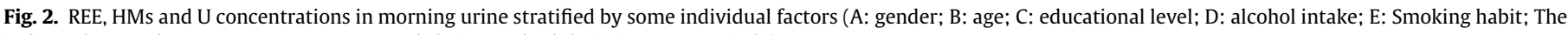
indicate bars and errors represent means and their standard deviation, respectively). 

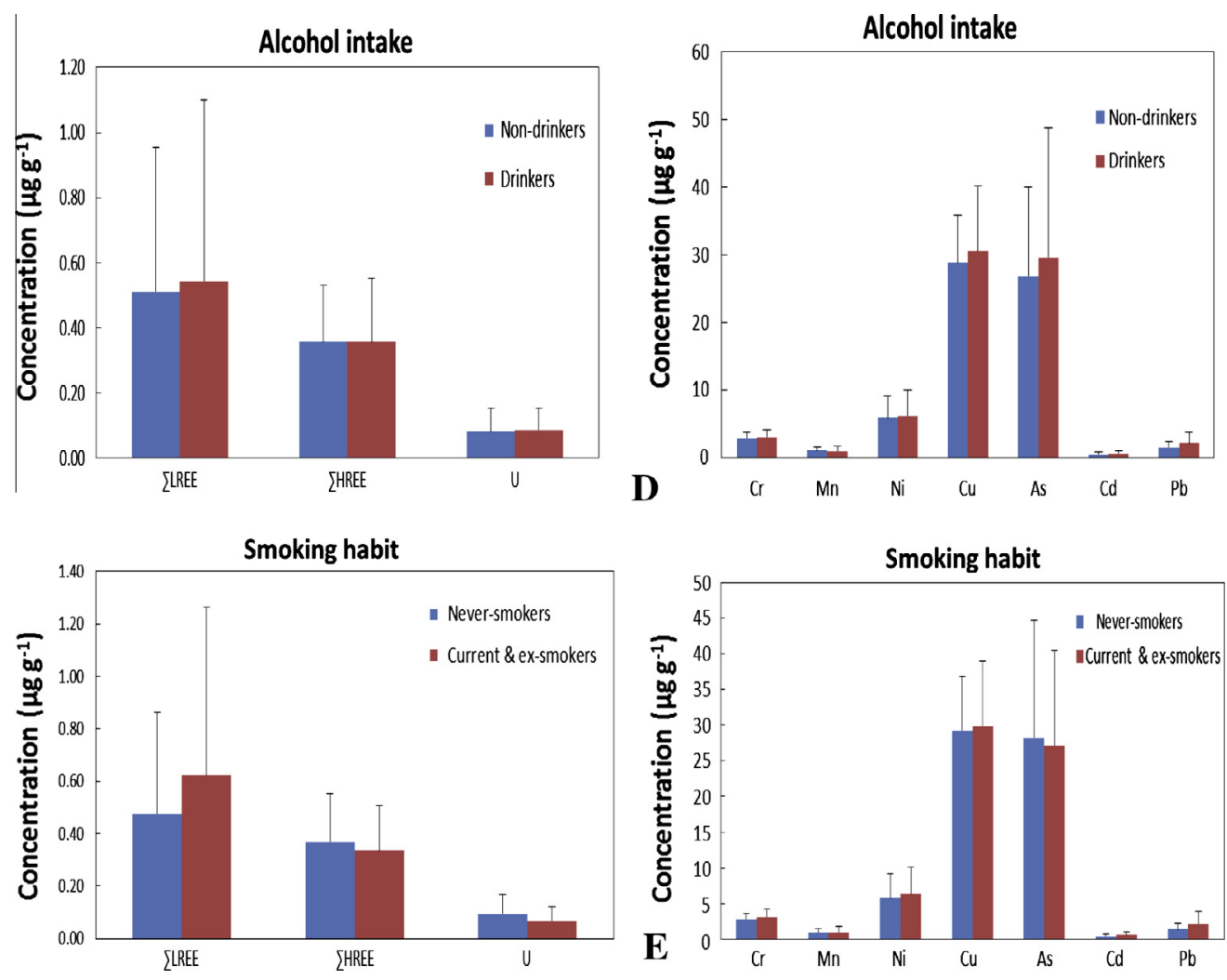

Fig. 2 (continued)

and females may differ in degree. The relationships between gender and the trace element concentrations are presented in Fig. 2A. The results in both Table 5 and Fig. 2A show that the mean concentrations of REE, HMs and $U$ are higher in the males than those in the females on average. The mean concentration of Mn in males is a little lower than in the females. The differences in concentrations of $\mathrm{Cr}, \mathrm{Cd}, \mathrm{Pb}$ are statistically significant $(p<0.05)$, while differences in other elements do not achieve statistical significance. The results suggest that males are more exposed to REE and other metals than females. Gender differences in food intake, iron status, and hormonal influences can affect the absorption and bioavailability of metals (Olsson et al., 2002; Kazi et al., 2008).

\subsubsection{Variation in metal concentration by age groups}

The 128 participants in the mining area were divided into 3 age groups, which were the young age group (aged 18-29), the middle age group (aged 30-59) and the senior age group (aged 60-69). The relationships between age and trace metal concentrations are presented in Fig. 2B. For most trace elements, there is a trend that shows metal concentrations are highest in the young age group, then the middle age group, and lowest in the senior age group. However, for $\sum$ LREE, the concentrations in the senior age group rank highest. Based on the Student $t$-tests, the differences of $\mathrm{Cr}$, $\mathrm{Ni}$, As and $\mathrm{Pb}$ concentrations among the three age groups are significant $(p<0.05)$, which indicate the young age group is moreexposed to REE and other metals. It suggests that young people might absorb higher doses of metals through the environment and the trace metals in the body might decline with age. This finding differs from a study conducted in a sample of Andalusia population (Aguilera et al., 2008), where showed age-dependent increases in urinary levels of $\mathrm{Cr}$. The differences among age groups for other metals are not statistically observable. REE, U, Mn, Cu and $\mathrm{Cr}$ accumulated in people who are exposed to lower concentrations of heavy REE might not be associated with age.
3.2.3. Variation in metal concentration by educational level

The participants were divided into 3 groups according to their educational level: primary education, secondary education and university degree. The relationships between educational level and trace metal concentrations are presented in Fig. 2C. It shows that metal concentrations in people with only a primary education are the lowest, and the differences between secondary education and university degree are not statistically significant. Based on the Student $t$-tests, the differences of $\mathrm{Ni}$ and $\mathrm{Pb}$ concentrations are striking $(p<0.05)$. It suggests that people of lower educational levels are less likely to be exposed to the metals in the environment. In our research, there is a significant negative correlation between educational level and age $(p<0.05)$. People of higher educational level follow the same trend with those of young age group, who are more exposed to REE and other metals. However, educational level is a complex variable that may be a surrogate for other covariates, measured or unmeasured in this analysis, many of these associations are difficult to explain. The variations might due to the different and rather complex incorporation-kinetics of elements which have not been studied so far and elucidated in detail.

\subsubsection{Variation in metal concentration by drinking behavior}

The relationships between drinking behavior and trace metal concentrations are presented in Fig. 2D. The results in both Table 5 and Fig. 2D showed that except for Mn, the mean concentration of REE, heavy metals and $U$ are higher in people who drink alcohol compared to those people who never drink. The differences of $\mathrm{Cd}$ and $\mathrm{Pb}$ are statistically significant $(p<0.01)$, while other metals fail to achieve statistical significance. These results suggest that drinking may be a surrogate for life style and specific exposures that are related to life styles.

\subsubsection{Variation in metal concentration by smoking behavior}

The relationships between smoking behavior and trace metal concentrations are presented in Fig. 2E. It can be seen that smoking 
can increase the concentrations of LREE, $\mathrm{Cr}, \mathrm{Ni}, \mathrm{Cu}, \mathrm{Cd}$ and $\mathrm{Pb}$ in morning urine. The increase in $\mathrm{Cd}$ and $\mathrm{Pb}$ are statistically significant $(p<0.01)$. It has been previously reported that smoking clearly influences Cd concentrations (Hoffmann et al., 2000). Urinary $\mathrm{Cd}$ is considered an indicator of recent exposure (Gil et al., 2011) and this might explain the reason for higher Cd levels in smokers as compared to those who never smoke. As a counter factor, smoking can reduce the load of $\sum$ HREE, U, Mn and As. The mean concentration of $U$ in smokers is significantly lower than in non-smokers $(p<0.05)$.

In fact, some correlations between element concentrations and selected factors may due to chance or in other cases are not biologically or clinically remarkable and factors can be influenced by other covariates. In order to obtain the most reliable estimate of associations among urine concentrations and one categorical variable without the bias from other factors, we also compare data that are corrected for other covariates. After correction, differences in element concentrations by gender are no longer statistically significant except for $\mathrm{Pb}(p=0.044)$; By age groups, only differences of $\mathrm{Mn}$ and $\mathrm{Pb}$ are statistically observable; it shows no remarkable differences in element concentrations among educational level groups except for $\mathrm{Mn}(p=0.034)$; differences in all element concentrations are no longer statistically significant between drinkers and non-drinkers ; and the differences of $\mathrm{Cd}, \mathrm{Pb}$ and $\mathrm{U}$ achieve statistically significance stratified by smoking habit. In some cases, correction for confounders and covariates changed significance of the differences. In addition, there are some other confounders such as environmental factors that may affect the complex incorporation-kinetics of elements, and influence their concentrations as a result. Some associations are difficult to explain and need further research.

\section{Conclusions}

The concentrations of $\sum$ LREE, $\sum$ HREE, $\sum$ HMs and U in morning urine in the Baiyun Obo mining area are higher than those from the control area, respectively. It can be concluded that the environment in the mining area has been influenced by the rare earth mining process. The pollution of REE in Baiyun Obo is mainly from LREE. Besides REE, heavy metal and radionuclide pollution are also produced with REE exploitation. Males and people in the young age group are more exposed to the metals. The mean concentrations of REE, HMs and $U$ are usually higher in the urine of males than females from the mining area. For most trace elements, it shows a trend that metal concentrations in urine of the young age group are the highest, then the middle age, and those in the senior age group are the lowest. People in the low educational group are less likely to be exposed to metals in the environment mainly because of interaction effect between age and education level but this effect was not tested statistically. The behavior of drinking and smoking increases the likelihood of concentrations of LREE, $\mathrm{Cr}, \mathrm{Cu}, \mathrm{Cd}$ and $\mathrm{Pb}$ in morning urine, while these behaviors likely decrease the concentrations of HREE and Mn. Drinking can also likely increase the load of $U$ in morning urine to some degree. Counter factually, smoking also can reduce the likelihood of the concentration of $U$.

\section{Acknowledgments}

This work was supported by the Key Project of the Knowledge Innovation Program of IGSNRR (2012ZD002), the Special Fund for Agroscientific Research in the Public Interest (No. 201203012-6) and the Special Fund for the Public Interest Research of China MEP (No. 201209012).

\section{Appendix A. Supplementary material}

Supplementary data associated with this article can be found, in the online version, at http://dx.doi.org/10.1016/j.chemosphere. 2015.01.057.

\section{References}

Aguilera, I., Daponte, A., Gil, F., Hernandez, A.F., Godoy, P., Pla, A., Ramos, J.L., Grp, D., 2008. Biomonitoring of urinary metals in a population living in the vicinity of industrial sources: a comparison with the general population of Andalusia, Spain. Sci. Total Environ. 407, 669-678. http://dx.doi.org/10.1016/ j.scitotenv.2008.08.041.

Aguilera, I., Daponte, A., Gil, F., Hernandez, A.F., Godoy, P., Pla, A., Ramos, J.L., Grp, D., 2010. Urinary levels of arsenic and heavy metals in children and adolescents living in the industrialised area of Ria of Huelva (SW Spain). Environ. Int. 36, 563-569. http://dx.doi.org/10.1016/j.envint.2010.04.012.

Ardestani, M.M., van Straalen, N.M., van Gestel, C.A., 2014. Uptake and elimination kinetics of metals in soil invertebrates: a review. Environ. Pollut. 193, 277-295. http://dx.doi.org/10.1016/j.envpol.2014.06.026.

Belli, P., Bernabei, R., Cappella, F., Cerulli, R., Dai, C.J., Danevich, F.A., d'Angelo, A., Incicchitti, A., Kobychev, V.V., Nagorny, S.S., Nisi, S., Nozzoli, F., Prosperi, D., Tretyak, V.I., Yurchenko, S.S., 2007. Search for $\alpha$ decay of natural Europium. Nucl. Phys. A 789, 15-29. http://dx.doi.org/10.1016/j.nuclphysa.2007.03.001.

BGS (British Geological Survey, Natural Environment Research Council), 2011. Rare earth elements. BGS $\odot$ NERC, Nottingham, United Kingdom.

Cai, D.J., 2012. Contents of heavy metals in lotus seed from REEs mining area. J. Saudi Chem. Soc. 16, 175-176. http://dx.doi.org/10.1016/j.jscs.2010.12.004.

Castano, A., Sanchez-Rodriguez, J.E., Canas, A., Esteban, M., Navarro, C., RodriguezGarcia, A.C., Arribas, M., Diaz, G., Jimenez-Guerrero, J.A., 2012. Mercury, lead and cadmium levels in the urine of 170 Spanish adults: a pilot human biomonitoring study. Int. J. Hyg. Environ. Health 215, 191-195. http:// dx.doi.org/10.1016/j.ijheh.2011.09.001.

Castor, S.B., Hedrick, J.B., 2006. Rare earth elements, seventh ed.. In: Kogel, J.E., Trivedi, N.C., Barker, J.M., Krukowski, S.T. (Eds.), Industrial Minerals and Rocks: Commodities, Markets, and Uses Society for Mining, Metallurgy, and Exploration, Littleton, Colorado, p. 1568.

Chen, Z.H., 2011. Global rare earth resources and scenarios of future rare earth industry. J. Rare Earths 29, 1-6. http://dx.doi.org/10.1016/S10020721(10)60401-2.

Chen, Z.Y., 2005. Accumulation and toxicity of rare earth elements in brain and their potential effects on health. Rural Eco-Environ. 21, 72-73.

Chen, Z.Y., Zhu, X.D., 2008. Accumulation of rare earth elements in bone and its toxicity and potential hazard to health. J. Ecol. Rural Environ. 24, 88-91.

Cui, Y., Zhu, Y.G., Zhai, R., Huang, Y., Qiu, Y., Liang, J., 2005. Exposure to metal mixtures and human health impacts in a contaminated area in Nanning, China. Environ. Int. 31, 784-790. http://dx.doi.org/10.1016/j.envint.2005.05.025.

Du, X.Y., Graedel, T.E., 2013. Uncovering the end uses of the rare earth elements. Sci. Total Environ. 461, 781-784. http://dx.doi.org/10.1016/j.scitotenv.2013.02.099.

Feng, J., Zhang, H., Zhu, W.F., Liu, C.Q., Xu, S.Q., Wu, D.S., 2000. Bio-effect of rare earths in the high background region I. Some blood biochemical indices from population resided in light REE district. J. Rare Earth 18, 356-359.

Gao, H., 2009. General comments on rare earth and scarce resources in Baiyunebo. Sci. Technol. Baotou Steel 35, 1-6.

Gil, F., Hernández, A.F., Márquez, C., Femia, P., Olmedo, P., López-Guarnido, O., Pla, A., 2011. Biomonitorization of cadmium, chromium, manganese, nickel and lead in whole blood, urine, axillary hair and saliva in an occupationally exposed population. Sci. Total Environ. 409, 1172-1180. http://dx.doi.org/10.1016/ j.scitotenv.2010.11.033.

Guo, W., Zhao, R.X., Zhao, W.J., Fu, R.Y., Guo, J.Y., Bi, N., Zhang, J., 2013. Effects of arbuscular mycorrhizal fungi on maize (Zea mays L.) and sorghum (Sorghum bicolor L. Moench) grown in rare earth elements of mine tailings. Appl. Soil Ecol. 72, 85-92. http://dx.doi.org/10.1016/j.apsoil.2013.06.001.

Heitland, P., Koster, H.D., 2006. Biomonitoring of 30 trace elements in urine of children and adults by ICP-MS. Clin. Chim. Acta 365, 310-318. http://dx.doi.org/ 10.1016/j.cca.2005.09.013.

Hilsum, L., 2009. Chinese Pay Toxic Price for a Green World. The Sunday Times, London.

Hoffmann, K., Becker, K., Friedrich, C., Helm, D., Krause, C., Seifert, B., 2000. The German environmental survey 1990/1992 (GerES II): cadmium in blood, urine and hair of adults and children. J. Expo. Anal. Environ. Epidemiol. 10, 126-135. http://dx.doi.org/10.1038/sj.jea.7500081.

Hu, Z.Y., Haneklaus, S., Sparovek, G., Schnug, E., 2006. Rare earth elements in soils. Commun. Soil Sci. Plant Anal. 37, 1381-1420. http://dx.doi.org/10.1080/ 00103620600628680.

Hurst, C., 2010. China's Rare Earth Elements Industry: What can the West Learn? Institute for the Analysis of Global Security, Washington, DC. pp. 43.

Kanazawa, Y., Kamitani, M., 2006. Rare earth minerals and resources in the world. J. Alloys Compd. 408, 1339-1343. http://dx.doi.org/10.1016/ j.jallcom.2005.04.033.

Kazi, T.G., Afridi, H.I., Kazi, N., Jamali, M.K., Arain, M.B., Jalbani, N., Kandhro, G.A., 2008. Copper, chromium, manganese, iron, nickel, and zinc levels in biological samples of diabetes mellitus patients. Biol. Trace Elem. Res. 122, 1-18. http:// dx.doi.org/10.1007/s12011-007-8062-y. 
Kitamura, Y., Usuda, K., Shimizu, H., Fujimoto, K., Kono, R., Fujita, A., Kono, K., 2012. Urinary monitoring of exposure to yttrium, scandium, and europium in male wistar rats. Biol. Trace Elem. Res. 150, 322-327. http://dx.doi.org/10.1007/ s12011-012-9494-6.

Li, J., 2008. Utilization current situation, main problems and solving countermeasures of Baiyunebo rare-earth resources. J. Shanxi Norm. Univ. 22, $76-77$.

Meng, L.L., Wang, J., Li, J., 2009. Thinking on protection and strategic reserves of rare earth resources in Baotou. Sci. Technol. Baotou Steel Corp. 35, 6-8.

Moon, C.S., Zhang, Z.W., Shimbo, S., Watanabe, T., Lee, C.U., Lee, B.K., Ahn, K.D., Lee, S.H., Ikeda, M., 1999. Evaluation of urinary cadmium and lead as markers of background exposure of middle-aged women in Korea: dietary intake as an influential factor. Toxicol. Lett. 108, 173-178. http://dx.doi.org/10.1016/S03784274(99)00086-7.

Morton, J., Tan, E., Leese, E., Cocker, J., 2014. Determination of 61 elements in urine samples collected from a non-occupationally exposed UK adult population. Toxicol. Lett. http://dx.doi.org/10.1016/j.toxlet.2014.08.019.

Olsson, I.M., Bensryd, I., Lundh, T., Ottosson, H., Skerfving, S., Oskarsson, A., 2002. Cadmium in blood and urine-impact of sex, age, dietary intake, iron status, and former smoking-association of renal effects. Environ. Health Perspect. 110, 1185-1190.

Pang, X., Li, D.C., Peng, A., 2002. Application of rare-earth elements in the agriculture of China and its environmental behavior in soil. Environ. Sci. Pollut. Res. 9, 143148. http://dx.doi.org/10.1007/BF02987462.

Paul, J., Campbell, G., 2011. Investigating rare earth element mine development in EPA region 8 and potential environmental impacts. Additional review by Region 8 Mining Team Members, Washington, DC, Environmental Protection Agency (US), Report No.: EPA Document-908R11003.

Protano, G., Riccobono, F., 2002. High contents of rare earth elements (REES) in stream waters of a $\mathrm{Cu}-\mathrm{Pb}-\mathrm{Zn}$ mining area. Environ. Pollut. 117, 499-514. http:// dx.doi.org/10.1016/S0269-7491(01)00173-7.

Rainbow, P.S., 2007. Trace metal bioaccumulation: models, metabolic availability, and toxicity. Environ. Int. 33, 576-582. http://dx.doi.org/10.1016/j.envint.2006. 05.007.

Rim, K.T., Koo, K.H., Park, J.S., 2013. Toxicological evaluations of rare earths and their health impacts to workers: a literature review. Saf. Health Work 4, 12-26. http://dx.doi.org/10.5491/SHAW.2013.4.1.12.

Schroijen, C., Baeyens, W., Schoeters, G., Den Hond, E., Koppen, G., Bruckers, L., Nelen, V., De Mieroop, E.V., Bilau, M., Covaci, A., Keune, H., Loots, I., Kleinjans, J., Dhooge, W., Van Larebeke, N., 2008. Internal exposure to pollutants measured in blood and urine of Flemish adolescents in function of area of residence.
Chemosphere 71, 1317-1325. http://dx.doi.org/10.1016/j.chemosphere.2007. 11.053.

Thomas, P.J., Carpenter, D., Boutin, C., Allison, J.E., 2014. Rare earth elements (REEs): effects on germination and growth of selected crop and native plant species. Chemosphere 96, 57-66. http://dx.doi.org/10.1016/j.chemosphere.2013.07.020.

Ukkola, O., Gagnon, J., Rankinen, T., Thompson, P.A., Hong, Y., Leon, A.S., Rao, D.C. Skinner, J.S., Wilmore, J.H., Bouchard, C., 2001. Age, body mass index, race and other determinants of steroid hormone variability: the HERITAGE family study. Eur. J. Endocrinol. 145, 1-9. http://dx.doi.org/10.1530/eje.0.1450001.

Vermeulen, A., Kaufman, J.M., Giagulli, V.A., 1996. Influence of some biologica indexes on sex hormone-binding globulin and androgen levels in aging or obese males. J. Clin. Endocrinol. Metab. 81, 1821-1826.

Vrijens, J., Leermakers, M., Stalpaert, M., Schoeters, G., Den Hond, E., Bruckers, L., Colles, A., Nelen, V., Van Den Mieroop, E., Van Larebeke, N., Loots, I., Baeyens, W., 2014. Trace metal concentrations measured in blood and urine of adolescents in Flanders, Belgium: reference population and case studies Genk-Zuid and Menen. Int. J. Hyg. Environ. Health 217, 515-527. http://dx.doi.org/10.1016/ j.ijheh.2013.10.001.

Wang, L.H., Huang, X.H., Zhou, O., 2008. Effects of rare earth elements on the distribution of mineral elements and heavy metals in horseradish. Chemosphere 73, 314-319. http://dx.doi.org/10.1016/j.chemosphere.2008. 06.004.

Wei, B.G., Li, Y.H., Li, H.R., Yu, J.P., Ye, B.X., Liang, T., 2013. Rare earth elements in human hair from a mining area of China. Ecotoxicol. Environ. Saf. 96, 118-123. http://dx.doi.org/10.1016/j.ecoenv.2013.05.031.

WHO, 1996. Biological monitoring of chemical exposure in the workplace, vol. 1 World Health Organization, Geneva.

Wu, C.Y., 2008. Bayan Obo Controversy: carbonatites versus iron oxide-Cu-Au-(REEU). Resour. Geol. 58, 348-354. http://dx.doi.org/10.1111/j.1751-3928.2008. 00069.x.

Xie, Q., Ouyang, L., Wang, J., 2012. Determination and correlation analysis of light rare earth elements in humans blood, food, urine and feces by ICP-MS. J. Chin. Mass Spectrom. Soc. 33, 353-356.

Xu, Q., Liu, X.D., Tang, Q.F., Liu, J.C., Zhang, L.J., 2011. A multi-element survey of surface soil and pollution estimate in Baotou city. Arid Land Geogr. 34, 91-99.

Zhang, L., Wang, L., Liu, Q. Zhang, L., Zhang, J., 2001. A survey on the death cause of redients in Baiyun Obo district, Baotou City from 1995 to 1997. J. Baotou Med. Coll. 17, 7-9.

Zitzmann, M., Nieschlag, E., 2001. Testosterone levels in healthy men and the relation to behavioural and physical characteristics: facts and constructs. Eur. J. Endocrinol. 144, 183-197. http://dx.doi.org/10.1530/eje.0.1440183. 